\title{
The Impact of Land Fragmentation in the Qualitative and Quantitative Aspect of Seeds and Their Production
}

\author{
Bleza Teneqexhi \\ Agricultural University of Tirana, Tirana, Albania \\ Arjola Luci \\ Financial Specialist, Tirana, Albania
}

Due to the pedo-climate conditions in the region of Korca, this area is considered to be one of the most favorable regions for cultivating various kinds of plants such as cereals, vegetables, wood-trees, vineyards, etc. All the factors such as rain, temperature, the impact of sunlight, and the pathological structure of the land, make this region one of the most productive and qualitative among the others. Changing the political systems in Albania during the last decades in Albania had its own impact even in the agricultural aspect. Shifting from communism into a modern, capitalist economy built a huge barrier for farmers in their way to intensifying the agricultural production. Dividing the land according to the law number 7,501, was accompanied by a severe fragmentation of the plot, reducing the degree of mechanization and chemical process. In this paper, the authors will try to analyze the effect of law fragmentation in the regional farmers working process in the region of Korca, and other municipalities such as Bilisht and Maliq, nearby Korca. There were randomly interviewed 150 farmers, from which 30 from the municipality of Bilisht, 22 from Korca municipality and 15 from Maliqi. From each farmer, these were the variables taken into consideration: Total land area, irrigated land, the number of plots, the area planted with wheat, corn, vegetables, fruit, vineyards, and forages. All the data that were gathered and translated into figures have indicated statistic elements such as the average value of each variable, deviation or standard deviation, coefficient of variation, correlation and regression. For instance in the municipality of Bilisht, it has been concluded that between the total variable area and number of plots, the related correlation value of the correlation coefficient is $r=$ +0.73 and the value of regression coefficient is $R=2.71$. In this municipality, correlative links between the variable and the total area planted with wheat area, are of medium category, with a value of the correlation coefficient of $r=+0.52$ and the regression coefficient is $R=0.89$. Regarding the studies in the municipality of Maliq, it has been a correlation link between the weak variable category: in the surface of the irrigated area and the land planted with vegetables and corn, the value of the correlation coefficient is $r=+0.24$ and the regression coefficient $R=2.11$. In the municipality of Korca, among the variable of irrigated area and the surface of the land planted with vegetables, there is a weak correlative link with a value of the correlation coefficient $r=+0.17$ and the regression coefficient $R=0.58$.

Keywords: statistical processing, correlation coefficient, regression, variable plant species

Bleza Teneqexhi, Ph.D. candidate, Head of financial Department, Agricultural University of Tirana, Tirana, Albania. Arjola Luci, M.Sc., financial specialist at a private sector, Tirana, Albania.

Correspondence concerning this article should be addressed to Bleza Teneqexhi, Rr “3 Deshmoret”, Pall “Artemon”, Tirane, Albania. 


\section{Introduction}

Our land is an essential and irreplaceable means of agricultural production and farming. If we do not pay enough attention in order to maintain a certain degree of welfare, it is for sure that the negative effects that will be seen in the future will impact not only the quality of its products but also its own safeness, let alone the impact on increasing the odds of erosion and its degradation.

Being an eco-region involved in the pre-mountain climate with altitudes from sea level among $800 \mathrm{~m}-950$ $\mathrm{m}$ and with sufficient annual rainfall, all the cultivated plants find favorable conditions for vegetation. Changing the economic system in Albania, shifting from communism into free market economy, was also companied by a different agricultural management, which means that every farmer has its own fragmented plots that ranged from six to eight pieces.

However, this kind of fragmentation adversely affected the agricultural production because of the mechanization and lowered the intensifying process. In order to scientifically express this process, we have been interviewing 150 active farmers form the three municipalities of Korca, including those of Maliq and Bilisht. In the questionnaires handed to the farmers, the criteria that were taken into consideration dealt mainly with the total area of land, the area of irrigated land, the number of plots, and the structure of sowing plants that most of the farmers grow in this region. The variables listed in this questionnaire were collected separately for each municipality and then they were statistically prepared calculating statistical elements that reflect the truth providing relevant covariance.

\section{Gathered Material and Methodology}

In order to obtain the most certain conclusion regarding our issues of fragmentation, there have been interviewing 150 active famers from all the municipalities that are included in the region of Korca. Randomly there have been selected 67 active farmers, who were previously questioned with the following information regarding: the total area, the area of irrigated land, the number of plots, the structure of cultivated plants, wheat, corn, vegetables, fruit, vineyards, and fodder. All the listed variables in this questionnaire were collected for each municipality, whereupon statistical processing of their estimated covariance as well as correlation and regression relationships. In Korca were randomly selected 22 active farmers in 10 villages, in Bilisht 30 farmers from eight villages, and in Maliq, which is smaller municipality, were selected 15 farmers from five villages.

\section{Results and Discussions}

In the municipality of Bilisht were selected 30 farmers from eight villages and according to the statistics it resulted that there were 470 acres of land cultivation, of which 298 as irrigated land or in other words $63.4 \%$ of them are located in 121 plots.

According to the results taken from the statistic process, we had come to the conclusion that there is a correlation value of the correlation coefficient of $r=+0.73$ and a value of regression with the coefficient $R=$ 2.77. This value is between two variables which reflect a high level of fragmentation plots.

Also in this municipality were analyzed other variables such as total surface and the area planted with wheat. According to the analysis of covariance, it appears to have a secondary link between them, the value of the correlation coefficient $r=+0.52$ and the value of regression coefficient $R=0.89$. On the other hand, in the municipality of Maliq was conducted correlation analyzes between variables total area and number of plots. In this area it was clearly conducted a bigger fragmentation and according to the analyses there was a value of 
correlation $r=+0.42$ and that of regression with a coefficient of $R=4.56$. There were also held variables of land surfaces with irrigated land and the areas planted with vegetables. According to the correlation analyses conducted among them, it results that there is a value of correlation with $r=+0.24$ and that of regression $R=$ 2.11. In Korca municipality, the areas with irrigated land plots make up a total of 225 acres or $57 \%$ of total cultivation area.

Statistical processing of all the data gathered from the figures among the variables: total area + vegetables and corn crops, appears to have a weak value of link correlation with an amount of the correlation coefficient $r$ $=+0.17$ and the regression one of $R=0.58$.

\section{Conclusions}

The phenomenon of fragmentation of the plots is an evident phenomenon in the three municipalities of the region of Korca, but with a difference in coefficients, however still very close to each other.

In Maliq municipality, among the variables: the total area and the number of plots, it results a medium value of correlation with an amount of correlation coefficient $r=+0.42$.

In Maliq, the value of the correlation coefficient between variables: area of land irrigated and vegetable crops is corn $+r=+0.24$.

In the municipality of Bilisht, which is also known as a very intensive cultivable area, among variables: total area and number of plots, the strong correlation related value of the correlation coefficient $r=+0.73$.

Among the variables: total and variable surface area with areas planted with wheat, it has an about medium correlation value of the correlation coefficient $r=+0.52$.

In the municipality of Korca, the value of correlation coefficient among variables: total amount of surface and the number of plots, results that there is no correlative link since the value of correlation coefficient $r$ is bigger than 1 . While among variables of irrigated areas and areas of land planted with vegetables, there's a weak link value of correlation with the correlation coefficient $r=+0.17$.

\section{Bilisht Municipality}

Link among total surface

$\bar{x}=15.66$

$\sqrt{x}=4.37$

$\sqrt{x} \cdot \sqrt{y}=5.07$

$\bar{x} \cdot \bar{y}=62.64$

$\overline{x \cdot y}=69.36$

$r= \pm \frac{(\sqrt{x} \cdot \sqrt{y})}{\bar{x} \cdot \bar{y}-\bar{x} \cdot \bar{y}}$

$r=+0.73$

$R=r \cdot \frac{\sqrt{x}}{\sqrt{y}}=0.73 \cdot \frac{4.37}{1.16}=2.71$

$R=2.71$

\section{Number of plots areas}

$\bar{y}=4.0$

$\sqrt{y}=1.16$

$$
r=\frac{5.07}{6.92}=+0.73
$$


Link among total surface

$\bar{x}=15.66$

$\sqrt{x}=4.37$

$\sqrt{x} \cdot \sqrt{y}=11.05$

$\bar{x} \cdot \bar{y}=78.30$

$\overline{x \cdot y}=99.48$

$r= \pm \frac{(\sqrt{x} \cdot \sqrt{y})}{\bar{x} \cdot \bar{y}-\bar{x} \cdot \bar{y}}$

$r=+0.52$

$R=r \cdot \frac{\sqrt{x}}{\sqrt{y}}=0.52 \cdot \frac{4.37}{2.53}=0.89$

$R=0.89$

\section{Bilisht Municipality}

Under-water surface

$\bar{x}=9.93$

$\sqrt{x}=5.85$

$\sqrt{x} \cdot \sqrt{y}=15.09$

$\bar{x} \cdot \bar{y}=30.08$

$\overline{x \cdot y}=48.23$

$r= \pm \frac{(\sqrt{x} \cdot \sqrt{y})}{\bar{x} \cdot \bar{y}-\bar{x} \cdot \bar{y}}$

$r=+0.83$

$R=r \cdot \frac{\sqrt{x}}{\sqrt{y}}=0.83 \cdot \frac{5.85}{2.58}=1.87$

$R=1.87$

\section{Korca Municipality}

Relevance correlation total area

$\bar{x}=19.7$

$\sqrt{x}=7.77$

$\sqrt{x} \cdot \sqrt{y}=52.05$

\section{Corn surface}

$\bar{y}=5.0$

$\sqrt{y}=2.53$

$r=\frac{11.05}{21.18}=+0.52$

$($ Corn + Vegetable $)$

$$
\bar{y}=3.03
$$

$\sqrt{y}=2.58$

$r=\frac{15.09}{48.28-30.08}=\frac{15.09}{18.15}$

The number of plots

$\bar{y}=6.05$

$\sqrt{y}=6.7$ 
$\bar{x} \cdot \bar{y}=119.18$

$\overline{x \cdot y}=133.40$

$r= \pm \frac{(\sqrt{x} \cdot \sqrt{y})}{\bar{x} \cdot \bar{y}-\bar{x} \cdot \bar{y}}$

$r=>1$

Correlation link of irrigated area

Vegetable + Corn

$\bar{x}=15.0$

$\bar{y}=4.85$

$\sqrt{x}=6.92$

$\sqrt{y}=2.03$

$\sqrt{x} \cdot \sqrt{y}=14.11$

$\bar{x} \cdot \bar{y}=72.75$

$\overline{x \cdot y}=146.92$

$r= \pm \frac{(\sqrt{x} \cdot \sqrt{y})}{\bar{x} \cdot \bar{y}-\bar{x} \cdot \bar{y}}$

$r=\frac{12.73}{146.92-72.75}=\frac{12.73}{74.17}$

$r=+0.17$

$R=r \cdot \frac{\sqrt{x}}{\sqrt{y}}=0.17 \cdot \frac{6.92}{2.03}=0.58$

$R=0.58$

\section{Korca Municipality}

Total Surface Corn

planted areas surface

$\bar{x}=19.7$

$\bar{y}=8.06$

$\sqrt{x}=7.77$

$\sqrt{y}=5.83$

$\sqrt{x} \cdot \sqrt{y}=45.30$

$\bar{x} \cdot \bar{y}=158.78$

$\overline{x \cdot y}=187.50$

$r= \pm \frac{(\sqrt{x} \cdot \sqrt{y})}{\bar{x} \cdot \bar{y}-\bar{x} \cdot \bar{y}}$

$r=\frac{45.30}{28.72}$

$r=>1$

\section{Maliq Municipality}

Link of total surface

Number of plots

$\bar{x}=15.73$

$\bar{y}=3.46$

$\sqrt{x}=13.04$

$\sqrt{y}=1.20$

$\sqrt{x} \cdot \sqrt{y}=15.64$ 
$\bar{x} \cdot \bar{y}=91.33$

$\overline{x \cdot y}=69.36$

$r= \pm \frac{(\sqrt{x} \cdot \sqrt{y})}{\overline{x . y}-\bar{x} \cdot \bar{y}}$

$r=\frac{15.64}{36.91}=+0.42$

$r=+0.42$

$R=r \cdot \frac{\sqrt{x}}{\sqrt{y}}=0.42 \cdot \frac{13.04}{1.20}=4.56$

$R=4.56$

Irrigated area surface

(Corn + vegetable)

$\bar{x}=9.33$

$\bar{y}=2.60$

$\sqrt{x}=13.72$

$\sqrt{y}=1.56$

$\sqrt{x} \cdot \sqrt{y}=21.40$

$\bar{x} \cdot \bar{y}=24.25$

$\overline{x \cdot y}=113.00$

$r= \pm \frac{(\sqrt{x} \cdot \sqrt{y})}{\bar{x} \cdot \bar{y}-\bar{x} \cdot \bar{y}}$

$r= \pm \frac{21.40}{88.75}=+0.24$

$r=+0.24$

$R=r \cdot \frac{\sqrt{x}}{\sqrt{y}}=0.24 \cdot \frac{13.72}{2.581 .56}=2.11$

$R=2.11$

Bilisht Municipality

\begin{tabular}{llllllllllll}
\hline No. & Village & $\begin{array}{l}\text { Acres } \\
\text { surface }\end{array}$ & $\begin{array}{l}\text { Irrigated } \\
\text { area }\end{array}$ & $\begin{array}{l}\mathrm{Nr} \\
\text { of plots }\end{array}$ & Wheat & Corn & Vegetables Fruits & Vineyards Fodder & Others \\
\hline 1 & Menkulas & 20 & 10 & 5 & 10 & 5 & 2 & - & - & 3 & - \\
2 & Vidohovë & 12 & 2 & 4 & 8 & 1 & 3 & - & - & - & - \\
3 & Hoçisht & 16 & 14 & 4 & 8 & 2 & 4 & - & 2 & - & - \\
4 & Shuec & 15 & 5 & 5 & 7 & 3 & 5 & - & - & - & - \\
5 & Sul & 20 & 15 & 4 & 10 & 5 & 3 & - & 2 & - & - \\
6 & Bilisht & 14 & 14 & 2 & - & - & 14 & - & - & - & - \\
7 & Bitinckë & 9 & 6 & 4 & 2 & 2 & 2 & 3 & - & - & - \\
8 & Bitinckë & 7 & 3 & 3 & 4 & 2 & 1 & - & - & - & - \\
9 & Bitinckë & 16 & 10 & 8 & 4 & 5 & - & - & 2 & 5 & - \\
10 & Bitinckë & 7 & 5 & 2 & 3 & 2 & 1 & 1 & - & - \\
11 & Bitinckë & 10 & 7 & 3 & 3 & 2 & 2 & - & - & 3 & - \\
12 & Hoçisht & 26 & - & 8 & 10 & 5 & - & 2 & 3 & 6 & - \\
13 & Hoçisht & 15 & 15 & 3 & - & - & - & 12 & 3 & - & - \\
14 & Bitinckë & 16 & 11 & 6 & 4 & 5 & 2 & 2 & 3 & - & - \\
15 & Hoçisht & 6 & 6 & 2 & 2 & - & 2 & - & - & 2 \\
16 & Vishocicë & 10 & 5 & 3 & 3 & 1 & 2 & 1 & 1 & 2
\end{tabular}


Bilisht Municipality to be continued

\begin{tabular}{|c|c|c|c|c|c|c|c|c|c|c|c|}
\hline No. & Village & $\begin{array}{l}\text { Acres } \\
\text { surface }\end{array}$ & $\begin{array}{l}\text { Irrigated } \\
\text { area }\end{array}$ & $\begin{array}{l}\mathrm{Nr} \\
\text { of plots }\end{array}$ & Wheat & Corn & Vegetables & Fruits & Vineyards & Fodder & Others \\
\hline 17 & Vishoshicë & 12 & 6 & 3 & 4 & 4 & 3 & - & - & 1 & - \\
\hline 18 & Vishoshicë & 25 & 15 & 5 & 5 & 5 & 1 & 4 & 2 & 3 & 5 \\
\hline 19 & Bitinckë & 11 & 4 & 3 & 4 & 2 & 2 & 2 & 1 & - & - \\
\hline 20 & Bitinckë & 8 & 3 & 3 & 2 & 2 & 3 & - & - & 1 & - \\
\hline 21 & Vishoshicë & 10 & 5 & 3 & 6 & 3 & 1 & - & - & - & - \\
\hline 22 & Hoçisht & 20 & 15 & 3 & 5 & 7 & 4 & - & - & 4 & - \\
\hline 23 & Hoçisht & 30 & 20 & 6 & 10 & 5 & 2 & 2 & - & 10 & 1 \\
\hline 24 & Vishocicë & 15 & 10 & 4 & 5 & 5 & 2 & - & - & 3 & - \\
\hline 25 & Vishoshicë & 20 & 12 & 4 & 5 & 5 & 2 & 5 & - & 3 & - \\
\hline 26 & Baban & 11 & 8 & 2 & 6 & 2 & 3 & - & - & - & - \\
\hline 27 & Baban & 21 & 21 & 4 & - & - & 12 & 5 & 4 & - & - \\
\hline 28 & Baban & 20 & 18 & 4 & 5 & 5 & 3 & 2 & 2 & 3 & - \\
\hline 29 & Gracë & 30 & 25 & 5 & 10 & 10 & 3 & 2 & 2 & 3 & - \\
\hline 30 & Menkulas & 18 & 8 & 6 & 7 & 2 & 1 & 2 & 2 & 4 & - \\
\hline Shuma & $\sum$ & 470 & 298 & 121 & 152 & 97 & 85 & 45 & 29 & 56 & 6 \\
\hline Mesat & $\bar{X}$ & $\overline{X 1}=15.66$ & $\bar{X} 2=9.93$ & $\bar{X} 3=4.0$ & $\bar{X} 4=5.0$ & $\bar{X} 5=3.2$ & $\bar{X} 6=2.87$ & $\bar{X} 7=1.5$ & $\bar{X} 8=0.97$ & $\bar{X} 9=1.87$ & $\bar{X} 10=0.20$ \\
\hline Shkuadrat & $\sqrt{ }$ & $\sqrt{1}=6.37$ & $\sqrt{2}=5.95$ & $\sqrt{3}=1.56$ & $\sqrt{4}=2.53$ & $\sqrt{5}=2.11$ & $\sqrt{6}=3.03$ & $\sqrt{7}=3.06$ & $\sqrt{8}=1.49$ & $\sqrt{9}=3.55$ & $\sqrt{10}=2.15$ \\
\hline
\end{tabular}

\section{Korca Municipality}

\begin{tabular}{|c|c|c|c|c|c|c|c|c|c|c|}
\hline No. & $\sum s . p$ & $\begin{array}{l}\text { Irrigated } \\
\text { area }\end{array}$ & $\begin{array}{l}\text { No. of } \\
\text { plots }\end{array}$ & Wheat & Corn & Vegetables & Fruits & Vineyards & Fodder & Others \\
\hline 1 & 23 & 16 & 7 & 4 & 2 & 2 & 9 & 1 & 5 & - \\
\hline 2 & 20 & 20 & 6 & 20 & - & - & - & - & - & - \\
\hline 3 & 21 & 15 & 6 & 3 & 3 & 2 & 4 & 2 & 7 & - \\
\hline 4 & 38 & 15 & 8 & 16 & - & 6 & 15 & 1 & - & - \\
\hline 5 & 18 & 14 & 7 & 6 & 6 & - & 1 & - & 5 & - \\
\hline 6 & 26 & 26 & 8 & 8 & 7 & 8 & - & - & 3 & - \\
\hline 7 & 32 & 28 & 12 & 5 & 10 & 6 & 10 & 1 & - & - \\
\hline 8 & 20 & 20 & 8 & - & - & 6 & 14 & - & - & - \\
\hline 9 & 20 & 15 & 7 & 5 & 5 & 5 & 5 & - & - & - \\
\hline 10 & 22 & - & 7 & 10 & - & - & 5 & 5 & 2 & - \\
\hline 11 & 16 & - & 5 & 8 & 2 & - & - & 5 & 1 & - \\
\hline 12 & 23 & - & 5 & 10 & 5 & - & - & - & 8 & - \\
\hline 13 & 25 & - & 7 & 10 & 5 & - & 5 & - & 5 & - \\
\hline 14 & 18 & - & 5 & 10 & 5 & - & 3 & - & - & - \\
\hline 15 & 12 & 8 & 4 & 4 & 4 & 4 & - & - & - & - \\
\hline 16 & 20 & 20 & 6 & 5 & 5 & 5 & - & - & 5 & - \\
\hline 17 & 21 & 13 & 5 & 5 & 4 & 6 & - & - & 6 & - \\
\hline 18 & 5 & 5 & 3 & - & - & 5 & - & - & - & - \\
\hline 19 & 9 & 5 & 3 & - & 4 & 5 & - & - & - & - \\
\hline 20 & 5 & 5 & 2 & - & - & 5 & - & - & - & - \\
\hline$\sum$ & 394 & 225 & 121 & 129 & 67 & 65 & 71 & 15 & 47 & - \\
\hline $\bar{X}$ & 19.7 & 15.0 & 6.05 & 8.06 & 4.07 & 5.0 & 7.1 & 2.50 & 4.70 & - \\
\hline$\sqrt{ }$ & 7.77 & 6.92 & 6.70 & 5.83 & 2.51 & 1.57 & 4.46 & 1.80 & 1.92 & - \\
\hline
\end{tabular}




\section{MALIQ Municipality}

\begin{tabular}{|c|c|c|c|c|c|c|c|c|c|c|c|}
\hline No. & Village & $\begin{array}{l}\text { Acres } \\
\text { surface }\end{array}$ & $\begin{array}{l}\text { Under-water } \\
\text { land }\end{array}$ & $\begin{array}{l}\text { No. of } \\
\text { plots }\end{array}$ & Wheat & Corn & Vegetables & Fruits & Vineyard & Fodder & Others \\
\hline 1 & Gurishtë & 60 & 60 & 5 & - & - & - & - & 60 & - & - \\
\hline 2 & Libonik & 15 & 7 & 3 & 5 & 5 & - & - & 5 & - & - \\
\hline 3 & Sheqeras & 25 & 5 & 2 & 10 & 5 & - & - & - & 10 & - \\
\hline 4 & Novoselë & 8 & 2 & 2 & 3 & 4 & 1 & - & - & - & - \\
\hline 5 & Vloçisht & 8 & 6 & 4 & - & - & - & 6 & - & 2 & - \\
\hline 6 & Vloçisht & 6 & 6 & 2 & 2 & 1 & - & - & - & 3 & - \\
\hline \multirow[t]{4}{*}{7} & Vloçisht & 10 & 6 & 4 & 1 & 1 & 3 & 1 & 1 & 3 & - \\
\hline & $\sum$ & 132 & 92 & 22 & 21 & 16 & 4 & 7 & 66 & 18 & - \\
\hline & $\overline{\bar{X}}$ & $\overline{X 1}=18.85$ & $\bar{X} 2=13.41$ & $\bar{X} 3=3.14$ & $\bar{X} 4=4.2$ & $\bar{X} 5=3.2$ & $\bar{X} 6=2$ & $\bar{X} 7=3.5$ & $\bar{X} 8=22$ & $\bar{X} 9=4.5$ & - \\
\hline & $\sqrt{ }$ & $\sqrt{1}=17.82$ & $\sqrt{2}=19.18$ & $\sqrt{3}=1.62$ & $\sqrt{4}=3.18$ & $\sqrt{5}=1.83$ & $\sqrt{6}=1.41$ & $\sqrt{7}=2.87$ & $\sqrt{8}=26.91$ & $\sqrt{9}=3.5$ & - \\
\hline 8 & Libonik & 20 & 9 & 6 & 10 & 5 & 4 & - & - & 1 & - \\
\hline 9 & Libonik & 10 & 5 & 3 & 3 & 2 & 2 & - & - & 3 & - \\
\hline 10 & Libonik & 15 & 7 & 3 & 5 & 5 & - & - & - & 5 & - \\
\hline 11 & Vloçisht & 8 & 2 & 2 & 3 & 3 & - & - & - & 2 & - \\
\hline 12 & Vloçisht & 6 & 6 & 4 & - & - & - & 4 & 2 & - & - \\
\hline 13 & Novoselë & 10 & 2 & 3 & 3 & 4 & - & - & - & 3 & - \\
\hline 14 & Gurishtë & 20 & 10 & 5 & 5 & 5 & 3 & 3 & - & 4 & - \\
\hline \multirow[t]{4}{*}{15} & Gurishtë & 15 & 7 & 4 & 5 & 4 & 3 & 3 & - & - & - \\
\hline & $\sum$ & 236 & 140 & 52 & 55 & 44 & 16 & 17 & 68 & 36 & - \\
\hline & $\overline{\bar{X}}$ & 15.73 & 9.33 & 3.46 & 3.66 & 2.93 & 2.28 & 2.83 & 17 & 3.6 & - \\
\hline & $\sqrt{ }$ & 13.04 & 13.72 & 1.20 & 2.85 & 1.66 & 1.01 & 1.71 & 24.86 & 2.36 & - \\
\hline
\end{tabular}

\section{References}

Allard, R. W. W. (1960). Principles of plant breeding.

Kume, K., \& Shima, X. H. (1974). Metodat e statistikës matematike në eksperimentin bujqësor.

Miller, F. (1980). Methods of statistics.

Eberhard, S. H., \& Rusell, E. A. (1966). Stability parameters for comparing varieties.

Guga, E. (1990). Aspekte metodike të provës fushore. 